\title{
10 Perception and imagination
}

\author{
A Sartrean account
}

\author{
Uriah Kriegel
}

\section{The perception/imagination distinction and Sartre}

Consider this very general question: What is the relationship between perception and imagination? When we consider this question, two facts pop out: (i) there is some commonality between the two, but (ii) there is a difference as well. Perception and imagination are alike in some respect(s), but also differ in some. The question is how to characterize the similarity and how to characterize the difference. Thus we may replace our single question with a pair: (Q1) What is the similarity between perception and imagination? (Q2) What is the dissimilarity between them?

These questions are still ambiguous, however, insofar as the terms "perception" and "imagination" are. The two nouns are most commonly used to denote putative faculties or capacities. These can be characterized in terms of the mental states they produce, or have the function of producing. Perception is the "faculty" that produces, or has the function of producing, perceptual states. Imagination is the faculty that produces, or has the function of producing, imaginative states. Thus Q1 and Q2 are best understood as ultimately about states (rather than faculties).

Imaginative states come in a several varieties. ${ }^{1}$ One distinction is between imagining an object and imagining awareness of the object: I can imagine a dog or imagine seeing a dog. ${ }^{2}$ Another distinction is between propositional and "objectual" imagining: I can imagine that Lena Dunham is elected president or I can imagine a purple dog. It is sometimes claimed that the relationship between objectual and propositional imagining is analogous to that between perceiving and believing (Currie and Ravenscroft 2002; McGinn 2004). But this is misleading. It is true that both the following are admissible reports of imaginative states:

(1) $S$ imagines $O$.

(2) $S$ imagines that $p$.

But a corresponding duality applies to perception reportage:

(1*) $S$ perceives $O$.

(2*) $S$ perceives that $p$. 


\section{Uriah Kriegel}

The relationship between 1 and 2 is analogous to that between $1^{*}$ and $2^{*}$. In both 2 and $2^{*}$, a propositional attitude is reported, but one which conceptually involves a sensuous dimension. By this I mean, it is part of the concepts of perceiving-that and imagining-that that some sensory experiences take place when a subject perceives-that or imagines-that. ${ }^{3}$ One might hold that occurrent beliefs or judgments also involve sensory experiences, but if so it is not part of the concept of belief or judgment that such experiences must take place. In that respect, believing is more analogous to conceiving, a kind of purely intellectual exercise of an imagination-like capacity. When one conceives that some water is not $\mathrm{H}_{2} \mathrm{O}$, one may experience sensory images of a watery substance, but it is not part of the concept of conceiving that such imagery must occur. In sum, my claim is that belief is to perception what conception is to imagination, not what propositional imagination is to objectual imagination. If we add:

(3) $S$ conceives that $p$

(3*) $S$ believes that $p$

we may say that the two series $1-2-3$ and $1 *-2 *-3 *$ parallel each other in a relevant sense.

The above distinctions reveal some ambiguity in Q1 and Q2. Here my focus will be on objectual perceptual and imaginative states-as opposed to propositional states or faculties/capacities. A further ambiguity concerns the type of similarity and dissimilarity we are interested in. Arguably, the most important similarities and differences between mental states concern (i) those pertaining to phenomenal character, in this case the subjective experience of perceiving and imagining, and (ii) those pertaining to functional role, in this case the role of perceiving and imagining within the subject's overall cognitive architecture. Both are important, but my concern in the present paper is specifically with phenomenal (dis)similarity. Thus, my topic is the following pair of questions: $\left(\mathrm{Q} 1_{\mathrm{p}}\right)$ What is the phenomenal similarity between perceiving $O$ and imagining $O$ ? $\left(\mathrm{Q}_{\mathrm{p}}\right)$ What is the phenomenal dissimilarity between perceiving $O$ and imagining $O ?^{4}$

$$
\text { «क }
$$

Approaches to this issue can be usefully divided into three groups. ${ }^{5}$ One traditional approach, more often implicit than argued for, is that perceiving and imagining are forsooth phenomenally indistinguishable. The only difference is extrinsic to the phenomenology: in the perceptual case the phenomenal state is accompanied by a belief that endorses its content, whereas in the imaginative case it is not. ${ }^{6}$ Another approach, associated with Hume, allows for phenomenal difference between perception and imagination, but only one of degree. ${ }^{7}$ The difference may concern phenomenal intensity, or resolution, or determinacy, but perceptual and 
imaginative experiences have the same kind of phenomenology. That is, they instantiate all the same phenomenal determinables, but differ with respect to instantiating their determinates. A third, more daring approach insists on a categorical or qualitative difference between perceptual and imaginative experience: there is a certain phenomenal determinable present in the one that is entirely absent from the other. We may call these the "no-difference" view, the "degree-difference" view, and the "kind-difference" view:

(ND) There is no phenomenal difference between perceiving $O$ and imagining $O$.

(DD) There is a phenomenal difference-in-degree ("quantitative" difference) between perceiving $O$ and imagining $O$.

$(\mathrm{KD})$ There is a phenomenal difference-in-kind (qualitative difference) between perceiving $O$ and imagining $O{ }^{8}$

Historically, ND and DD have dominated philosophical thinking about perception and imagination. Through a battery of phenomenological arguments, however, Sartre develops a formidable case against them. In what follows, I will use these arguments, or suitably strengthened versions, as a springboard for a broadly Sartrean answer to $Q 1_{p}$ and $Q_{p}$.

Sartre's interest in the imagination in fact predates all his later, better-known philosophical concerns. His 1926 thesis for an École Normale Supérieure diploma was about the imagination. His thesis director, one H. Delacroix, was a series editor at the publishing house Alcan, and asked Sartre for a book on the imagination (Contat and Rybalka 1970, pp. 50, 55). Of the book Sartre ended up writing, to be titled The Image, Alcan agreed to publish only the first half (see de Beauvoir 1960, pp. 168-171), under the title The Imagination (Sartre 1936). The second half was published four years later by the prestigious publisher Gallimard as The Imaginary (1940). Both books are organized around the question of the relationship between images and perceptions. The first presents a critical survey of failed accounts of imagination along the lines of ND and DD, with a diagnosis of their underlying error. The second develops a positive account of imagination in a $\mathrm{KD}$ vein.

It is worth noting that Sartre lumps together under the rubric of "the image" a great variety of phenomena. Three will concern me here: images we willingly and deliberately conjure up, as when I decide to form an image of a smiling octopus; images that pop up in our mind uninvited and fade out soon thereafter, as when an image of my mother's face appears to me suddenly; and images pertaining to episodic memory of individual objects or events, as when I suddenly remember the first giraffe I saw at a zoo. ${ }^{9}$ Let us call the first imaginative experiences, the second phantasmagoric experiences, and the third mnemonic experiences. ${ }^{10}$ In comparing the phenomenology of perception and imagination, my concern will be primarily with imaginative 


\section{Uriah Kriegel}

experiences, though phantasmagoric and mnemonic experiences will play a role later on. ${ }^{11}$

\section{Against the "classical conception"}

Surveying historical accounts of imagination, Sartre isolates a fundamental strand he calls the "classical conception." He identifies two central tenets in this classical conception. ${ }^{12}$ The first is a conception of the image as an object rather than act of consciousness, hence a "thing" among others; this is what Sartre (1936, p. 5/2012, p. 6) calls "thingism" (chosisme), which amounts essentially to a sense datum account of imaginative experience. The other, which will be our focus, is the assimilation of imagination to perception; this is ND:

We begin again with the assertion that sensation and image are identical in nature. We assert once more that an isolated image does not distinguish itself from an isolated perception. But this time the discrimination will be the product of a judgment-act (acte judicatif) of the mind.

(Sartre 1936, p. 101/2012, p. 91; my translation, italics original $)^{13}$

On this pernicious view, there is no essential difference between perceptual experience and imaginative experience considered intrinsically ("in isolation"). The only difference between the mind of the perceiver and the mind of the imaginer is in their second-order judgments about their experiences ("I am seeing a dog" vs "I am visualizing a dog"). These judgments must have certain grounds: there is a reason why one judges that one's experience is perceptual in some cases and that it is imaginative in others. It is part of the view Sartre considers that these judgments are based on interrelations among experiences (and standing beliefs). ${ }^{14}$ When one's experience coheres well with surrounding experiences and standing beliefs and expectations-when it is orderly, if you will-it is judged to be perceptual. When it is disorderly and incongruent, it is judged to be imaginative.

By my count, Sartre offers at least seven arguments against this "classical conception" of imagination. But the core of his case consists in a quartet of epistemological arguments of the following form: if perceptual and imaginative experiences were phenomenally indistinguishable, and distinguished only by accompanying judgments about their cohesion, our knowledge of whether we are perceiving or imagining would be very different from the way it really is.

First, if my knowledge that the dog presented by my current experience is perceived, rather than imaginary, were based on assessment of the experience's cohesion with other experiences, it would be a complex and somewhat impressive epistemic achievement. But this is false to the epistemology: 
Rather than the nature of the image as such [i.e., as being an image] being revealed to us by immediate intuition, we must finally make use of a system of infinite references in order to affirm of a content that it is an image or a perception ... Nobody will accept that recourse to a system of infinite references is needed to establish the discrimination between an image and a perception. Let everyone consult their internal experience.

(Sartre 1936, p. 102/2012, p. 93)

Bracketing certain hyperboles (e.g., implicating infinity), the basic idea is this. I know that I am imagining a dog not by comparing my experience to indefinitely many other experiences, but immediately, that is, without the mediation of any cognitive process of experience comparison. Call this the argument from immediacy: (1) we have immediate knowledge of whether we are perceiving or imagining; (2) if ND were true, we could not have such knowledge; so, (3) ND is false. ${ }^{15}$

Secondly, knowledge of whether I am imagining or perceiving is characterized not only by immediacy but also by a warranted feeling of certainty. Compare the judgments that $2+2=4$ and that there is salad for lunch. The former features a characteristic absent from the latter: a feel of certainty. Moreover, the feeling is not misplaced-one is warranted in having it. Such a warranted feeling of certainty appears also to characterize my current belief that I am seeing (and not merely imagining) a dog. But it is hard to see how it could have that characteristic if it were based on assessment of cohesion among complex, temporally extended series of experiences:

the discriminative judgment will only ever be probable ... We thus arrive at a paradoxical conclusion: far from the deep nature of the image being revealed to us by an immediate and certain knowledge, we will never be sure that such and such psychic contents on such and such a day and such and such an hour were really truly an image. Introspection is entirely deprived of its rights.

(Sartre 1936, p. 102/2012, p. 93)

Call this the argument from certainty: (1) our knowledge of whether we are perceiving or imagining exhibits a warranted feeling of certainty; (2) if ND were true, it would not; so, (3) ND is false.

Clearly, Sartre's central line of argument depends on a certain epistemology of first-person knowledge, whereby such knowledge is distinguished by special epistemic and psychological properties. There are of course deflationary accounts of self-knowledge that reject such a conception. Obviously, Sartre's case against ND falls apart if we adopt one of them. This is not the place to defend Sartre's epistemology of first-person knowledge, which arguably is a prerequisite for the kind of phenomenological inquiry he is engaged in. However, it bears stressing that nothing about this mode of 
argumentation requires that first-person knowledge be infallible, incorrigible, or otherwise extraordinarily enviable. It only requires that such knowledge be distinctive, that is, exhibit certain epistemic features absent in other kinds of knowledge. Furthermore, the claim need not be that this distinctive knowledge is always present when we introspect our perceptual and imaginary experiences; merely that it is present in ordinary or typical circumstances. ${ }^{16}$ This too is not beyond controversy (what is?), but it is much more innocuous to presuppose. ${ }^{17}$

A third epistemological argument, then, appeals to the effortlessness of first-person knowledge. If establishing that one is perceiving rather than imagining required sustained comparison with many other experiences and meticulous evaluation of their cohesion, it would be quite effortful. But, says Sartre, "Who has ever made so much effort to distinguish an image from a perception?" (1936, p. 104/2012, p. 94) Call this the argument from effort. ${ }^{18}$

A final epistemological argument may be called the argument from incongruence, as it rests on Sartre's phenomenological analysis of surprising, incongruent perceptual experiences:

I believe my friend Pierre to be in America. There I catch sight of him at the corner of the street. Will I tell myself "it's an image"? Not at all. My first reaction is to seek to find out how it is possible that he has already come back.

(Sartre 1936, p. 106/2012, p. 96)

Pierre's presence on a Paris street is unexpected (read: inconsistent with standing expectations). It is incongruent (coheres poorly with other experiences and beliefs). But this creates no tendency to classify one's experience as imaginative..$^{19}$ This suggests that the experience has an independent phenomenal feature which "marks" it as perceptual, and which one picks up on regardless of one's other experiences and expectations.

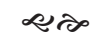

Might this phenomenal feature simply be the enhanced intensity or resolution of perceptual experiences, as DD maintains? Sartre's main argument against this is again epistemological ${ }^{20}$ :

For a sensation to cross the threshold of consciousness, it must have a minimum intensity. If images are of the same nature, they will have to have at least this intensity. But then won't we confuse them with sensations of the same intensity? And why does the image of a cannon-blast noise not appear as a weak but real cracking?

(Sartre 1936, p. 93/2012, p. 84; my translation)

Consider sensory perception of Hume's "minimal sensibilia," say hearing the faintest audible sound of a piece of furniture cracking; compare it to 
an imaginative experience of a deafeningly loud cannon blast a meter away. On the one hand, it is unclear in what sense the former may be said to be "more intense" than the latter. Certainly it is not louder. we could not even be aware of imaginary sounds, says Sartre, if they were less "loud" than minimal audibilia. (This remark is consistent both with the idea that imaginary noises have a loudness greater than minimal and with the idea-as it seems to me, more plausible-that they do not have a loudness at all, but only an imaginary-loudness.) On the other hand, DD cannot allow that imagining a deafeningly loud cannon is as phenomenally intense as perceiving minimally audible cracking, since it uses phenomenal intensity to separate the two categories to begin with. Either way, DD is unable to explain how we can tell by introspection alone whether we are perceiving or imagining when the phenomenal intensity is the same.

The same sort of argument would apply to other putative differences of degree between perception and imagination. Consider the view that perception is just an experience that uses a higher-resolution format than imagination. This is certainly the case with typical instances. But of course one can manually stretch the corners of one's eyes to blur one's visual experience increasingly, without at any point the experience changing status from vision to visualization..$^{21}$ More generally, as Byrne puts it,

for any episode of visualizing or recalling [a strawberry], it should be in principle possible to create a physical picture of a strawberry such that viewing the picture in certain conditions exactly reproduces the felt quality of visualizing or recalling. And this is what seems wrong [in Hume's view]: any way of degrading the picture, such as blurring, desaturating, dimming, and so on, just yields another perceptual experience, plainly [introspectively] discernable from visualizing or recalling.

(Byrne 2010, p. 17)

In other words, it is hard to see why the characteristic degradedness of an imaginative experience could not be matched by an intentional, willful degradation of a perceptual experience.

Another epistemological problem with DD is that it is unclear how it can allow for mixed episodes, as when I perceive the moon's front side, craters and all, and simultaneously imagine its back side, smooth and evensurfaced. DD seems to imply that my overall experience should be of a vivid cratered-moon image superimposed upon a faint smooth-moon image. But if that were the case, my introspection would surely suggest to me that I am having a perception of a craterish moon; but in fact it suggests to me that I am having simultaneous perceptual and imaginative experiences. ${ }^{22}$

It might be objected that first-person knowledge of perception and imagination is based not on the phenomenal character of the relevant experiences themselves, but on the processes by which they are formed. Compare and contrast: when my visual cortex computes a $15^{\circ}$ angle between two 


\section{Uriah Kriegel}

edges and produces a visual experience accordingly, I have no introspective insight into the process by which my experience was formed; but when I calculate 15 per cent of the bill and form a thought about the proper tip, I am introspectively aware of at least some aspects of the calculation process involved. Accordingly, the visual experience feels in some sense passive, while the thought feels active. This is the old contrast between receptivity and spontaneity in our mental life. The objector suggests that this contrast applies to perception and imagination: the former feels passive and receptive, the latter active and spontaneous (see Kind 2001, §3). Thus, when I imagine a dog I undergo an introspectively accessible personal-level process we might call the "creative exercise of imagination"; no such process takes place when I see a dog. On the objector's suggestion, I can tell by introspection whether my current experience is imaginative or perceptual by registering the presence or absence of this personal-level process. No difference need be assumed between the phenomenal characters of the perceiving and the imagining themselves.

This objection would be particularly embarrassing to Sartre, since he is explicitly committed to spontaneity as a distinguishing mark of imagination (Sartre 1940/2004, Ch.1 §4).$^{23}$ The obvious problem with it, however, is that it does not extend to mental images formed through sub-personal processes-what I have called above phantasmagoric experiences. When an unbidden image of a smiling octopus pops up in my mind, the process producing it is introspectively inaccessible to me-the popping-up of the image is something that happens to me, not something that I do. I feel receptive and passive rather than spontaneous and active. And yet I am perfectly capable of telling whether my experience is perceptual or phantasmagoric. So there must be a deeper dimension along which these two differ, which we may then reasonably assume also distinguishes perception and imagination.

In general, the notion that perception and imagination differ only with respect to degree (of vivacity, resolution, or what not) seems based on two ideas: that what makes an intentional state phenomenal is the format of representation it uses, and that perceptual and imaginative experiences use the same format. But Sartre vehemently rejects the format conception of phenomenality. He contrasts, in this context, awareness of public and mental images:

in the case [of public images], when the strictly imaging awareness had disappeared, there remained a sensible residue one could describe: it was the painted canvas or the spot on the wall ... [But with mental images,] when the imaging awareness is annihilated, its transcendent content is annihilated with it; there remains no residue one could describe ... We therefore cannot hope to grasp this content by introspection.

(Sartre 1940, p. 76/2004, p. 53; my translation) ${ }^{24}$ 
This passage anticipates Harman's (1990) rejection of "mental paint," an intrinsic, non-intentional format property of experiences. ${ }^{25}$ It makes clear why Sartre cannot accept any account of the perception/imagination distinction that implies a central role for representational format.

$$
\text { « }
$$

One objection to Sartre's argumentation is that there is a more plausible version of ND that he ignores. All versions of ND distinguish perception from imagination on the basis of accompanying beliefs. But while the version Sartre considers appeals to second-order beliefs about what experience the subject has, another version appeals to first-order beliefs about the ontological status of the experience's object. A perceptual experience is accompanied by the belief that its object is real, an imaginative experience by the belief that its object is unreal. On this version of ND, we know which experience we are having simply by knowing which first-order belief accompanies it; this neutralizes Sartre's epistemological arguments. Ignoring this version of ND remains a major lacuna in Sartre's critique, which we will have to address later on.

Bracketing this lacuna for now, the upshot of Sartre's argumentation is clear: there is a phenomenal difference between perceptual and imaginative experiences, and it is not merely a ("quantitative") difference in degree of intensity, resolution, or so on. It is a qualitative difference between two kinds of experience. It is "a difference of nature" (Sartre 1936, p. 91/2012, p. 83), "an intrinsic distinction" (Sartre 1936, p. 146/2012, p. 134), between two sui generis ways intentional objects appear to the subject (Sartre 1940, p. 24/2004, p. 13).

What is this categorical difference between perceptual and imaginative experience? In the final chapter of The Imagination, Sartre articulates an initial view whose inspiration he finds in Husserl's Ideen (Husserl 1913). However, in the final pages of The Imagination Sartre argues for a need to go beyond this initial view, and in the opening chapter of The Imaginary (published already as part of Sartre 1938), he articulates a refined view that goes beyond Husserl. I am much more attracted to the initial view, which I present and develop in the next section. In the section after that, I will turn to Sartre's argument for refining his initial view and offer reasons to resist it.

\section{Sartre's attitudinal account}

The initial view is formulated by Sartre in terms of the manner, or way, or mode of intentional directedness at an object. Here is a representative passage:

The image of my friend Pierre is not a vague phosphorescence, a wake left in my consciousness by the perception of Pierre. It is a form of organized consciousness that relates, in its manner, to my friend Pierre. It is 


\section{Uriah Kriegel}

one of the possible ways of aiming at the thing, Pierre ... [Accordingly, ] image is only a name for a certain way that consciousness aims at its object.

(Sartre 1936, p. 144/2012, pp. 132-133; italics mine) $)^{26}$

This passage raises two questions. First: how are we to understand this talk of manners and ways? (It would be nice to be able to "translate" this talk into the terminology of contemporary philosophy of mind.) Second: how can we characterize the difference between perceptual and imaginative manners or ways? (It would be nice to be told not only that the manners are different, but also how they are different.)

Sartre's talk of "manners" and "ways" of intentionally relating to an object may be understood in current-day terminology in terms of the distinction between attitude and content. Believing that $p$ and desiring that $p$ have the same content-they both represent that $p$. If beliefs and desires have intensity at all, we may stipulate that $S$ believes that $p$ and desires that $p$ with the same intensity. Still, they are clearly very different mental states. ${ }^{27}$ What they differ in is attitude: the specific relation they bear to $p$ is different. Consciously desiring that $p$ presents $p$ to the subject very differently from consciously believing that $p$. The two cast $p$ under very different lights. This attitudinal difference is clearly categorical: there is no continuum that leads us from a belief-end to a desire-end. ${ }^{28}$

According to Sartre, the difference between perceiving and imagining is of the same sort-it is an attitudinal difference. When I perceive my dog and when I imagine my dog, the dog presented in my experience is the same, and the intensity with which he is presented can be the same, but how it is presented is completely different-as different as how $p$ is represented in belief and in desire. Sartre writes:

The word "image" thus designates but the relation (rapport) that consciousness has to the object; in other words, it is a certain way the object has of appearing to consciousness, or if we prefer, a certain way consciousness has of giving itself an object. In truth, the expression "mental image" invites confusion. It would be better to say . . . "imaging consciousness of Pierre."

(Sartre 1940, p. 17/2004, p. 7; my translation) ${ }^{29}$

Speaking of a mental image of Pierre is ambiguous as between describing (i) an awareness of a Pierre-image and (ii) an image-awareness of Pierre. Only the latter is accurate. For in the latter, the image term modifies the intentional act, not the intentional object. It correctly casts the property of being imagistic as an attitudinal property of one's awareness. Call this the attitudinal account of the (phenomenal) difference between perception and imagination.

There is a traditional (and quite natural) view according to which seeing $O$ and hearing $O$ have the same content but differ in their mode or way of 
representing $O$. One uses a visual mode of representing $O$, the other uses an auditory mode; the difference is categorical. Within this framework, a proponent of the attitudinal account would insist that there is also a certain attitudinal commonality among all six perceptual modalities of representation, a commonality not shared by imagining $O$. Something about all six kinds of perceptual experience makes them perceptual, and whatever that is, it separates them from non-perceptual attitudes, including imaginings. Here too, the difference is one of kind, not degree: imagining $O$ is as categorically different from perceiving $O$ as seeing $O$ is from hearing $O$.

एक

How can we characterize attitudinal differences? For example, how can we characterize the difference between the belief-ish way of representing and the desire-ish way? There are familiar functional distinctions between the "belief box" and its inferential role and the "desire box" and its motivational role. But given our phenomenological concern, we are seeking a phenomenal distinction between the two. (I am assuming here, along with many others, that beliefs and desires do have phenomenal properties, including attitudinal ones. ${ }^{30}$ ) One promising suggestion is that conscious believing involves feeling it true that $p$ whereas conscious desiring involves feeling it good that $p$. L. J. Cohen develops this idea:

Feeling it true that $p$ may thus be compared with feeling it good that $p$. All credal feelings, whether weak or strong, share the distinctive feature of constituting some kind of orientation on the "True or false?" issue in relation to their propositional objects, whereas affective mental feelings, like those of anger or desire, constitute some kind of orientation on the "Good or bad?" issue.

(Cohen 1992, p. 11)

The same view is developed a century earlier by Franz Brentano. In Chapters 5-9 of Book II of his Psychology from an Empirical Standpoint, Brentano develops a systematic classification of mental phenomena based entirely on "different ways of being conscious of an object" (Brentano 1874, p. 201). A key difference is between cognitive acts of "judgment" and conative acts of "interest":

If something can become the content of a judgment in that it can be accepted as true or rejected as false, it can also become the object of [interest], in that it can be agreeable (in the broadest sense of the word) as something good, or disagreeable as something bad.

(Brentano 1874, p. 239)

The difference, then, is that cognitive states such as belief represent their contents as true, whereas conative states such as desire represent theirs as 


\section{Uriah Kriegel}

good (in some suitably general sense). This distinction is attitudinal, not content-based. Compare:

(B1) Belief $B$ represents $p$-as-true.

(B2) Belief $B$ represents-as-true $p$.

On the attitudinal view, B2 is the more accurate way of reporting the representational structure of belief; B1 is misleading. Similarly for desires:

(D1) Desire $D$ represents $p$-as-good.

(D2) Desire $D$ represents-as-good $p$.

Talk of manners/ways of representing should be understood as insisting that D2 is more accurate than D1.

If the belief/desire distinction comes down to a difference between representing-as-true and representing-as-good, what is the attitudinal distinction between perception and imagination? On this, Sartre's clearest passage is the following:

Every awareness posits its object, but each in its own manner. Perception, for example, posits its object as existent ... The intentional object of imaging awareness has this peculiarity that it is not there and it is posited as such, or that it does not exist and is posited as nonexistent, or that it is not posited at all.

(Sartre 1940, pp. 24-25/2004, p. 13; my translation)

The verb "to posit" is unfamiliar in analytic philosophy of mind, but in the Husserlian tradition it is commonly used to describe precisely the kind of attitudinal feature of an intentional act whereby it presents its object in a specific way. In this terminology, we would say that belief "posits" its content as true while desire "posits" it as good-without truth and goodness needing to enter the actual content of belief and desire.

With this in mind, the above passage suggests a straightforward view of perception's distinctive attitudinal feature: it represents its object as existing. This should be interpreted along $\mathrm{P} 2$ rather than $\mathrm{P} 1$ :

(P1) Perceptual experience $E$ represents $O$-as-existent.

(P2) Perceptual experience $E$ represents-as-existent $O$.

It is not part of the content of a perceptual experience that its object is real or existent. But the characteristic way perceptual experience represents its object is under the aspect of existence.

The view is more complicated when it comes to "imaging awareness" (conscience imageante), as the passage offers three different descriptors. The first casts the objects "as not there." In other passages, Sartre also speaks of 
acts that cast the object "as absent" and "as existing elsewhere." ${ }^{11}$ I propose that we formulate the canonical report of this kind of act as follows:

(I2.1) Imaging awareness $A$ represents-as-absent $O$.

Sartre's second descriptor more clearly calls for the following formulation:

(I2.2) Imaging awareness $A$ represents-as-non-existent $O$.

The third is odder: Sartre speaks of an object that is not posited at all. This might invite all sorts of mysterian readings, if it were not for Sartre's repeated insistence that all consciousness is consciousness-of, that is, intentional consciousness. Given this insistence, I think the only open interpretation is that Sartre has in mind a sensory analog of entertaining that $p$, contemplating that $p$, apprehending $p$, and the like "attidunally neutral" propositional attitudes. When you entertain or contemplate the proposition that there are more than eight provinces in Canada, you are in a state that presents the relevant proposition without commenting on its truth or goodness. Such states represent their propositional contents neither as true nor as good (nor otherwise). They represent them without commentary, so to speak. The objectual analog would be a mental state that represented $O$ while remaining neutral on $O$ 's ontological status. This suggests the following canonical report:

(I2.3) Imaging awareness $A$ merely-represents $O$.

Here $A$ is said to represent without representing-as. That is an intentional act that does not posit its object, that is, an "attitudinally neutral" objectual attitude. $^{32}$

From the passage itself, it is unclear whether Sartre proposes I2.1-I2.3 as (i) three antecedently plausible options for construing a single attitudinal feature of all imagery, or as (ii) three distinct attitudinal features actually exhibited by three different varieties of imagery. Sartre is in fact never explicit on this, but the tenor of his subsequent discussion suggests (ii). He thus seems committed to a certain heterogeneity among images. And indeed, recall that Sartre's subject matter is wider than just imagination and covers three different varieties of imagery-what I called imaginative, phantasmagoric, and mnemonic experiences. It would be nice if these mapped neatly on to I2.1-I2.3. Sartre nowhere suggests that they do, but I want to argue that it is independently plausible.

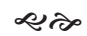

Consider imaginative experiences. These were characterized as experiences involving deliberate conjuring up of images. Here we exercise our imagination, 


\section{Uriah Kriegel}

we are "creative" in producing an image without exogenous stimulation. If one is already committed to a categorical attitudinal difference between such experiences and perceptual experiences, it is quite plausible to suppose that the difference is simply this: perceptual experiences represent-asexistent whereas imaginative experiences represent-as-non-existent. Thus, one difference between seeing my dog and visualizing a smiling octopus is that the former represents-as-existent the dog whereas the latter representsas-non-existent the octopus. It might be objected that we can also imagine things we know to exist, as when I visualize Barack Obama. But even here, it is plausible that my imaginative experience itself represents-as-non-existent what it represents; it is just accompanied by an overriding belief that the imagined object in fact exists. Compare: looking down from an airplane I see tiny houses and cars, but the visual experience is accompanied by a belief that these are in fact much bigger. If we try to abstract away from the accompanying beliefs, we recognize that imagining Obama in itself represents-as-non-existent that which is imagined. As I close my eyes and picture him, the Obama hovering just there on the other side of my desk is something I am aware of as unreal; the real Obama is in the White House talking to more important people. ${ }^{33}$

Consider next phantasmagoric experiences, where an image involuntarily pops up in one's mind. It is tempting to construe these as essentially continuous with imaginative experiences. On closer inspection, however, the fact that the imagination is not being consciously exercised, and the image is "spat out" by sub-personal processes, seems relevant. It makes it quite natural to propose that phantasms are in fact silent on the ontological status of their objects, presenting them "without commentary." If so, phantasmagoric experiences may well be attitudinally neutral in the above sense.

Finally, consider mnemonic experience, the imagery often implicated in episodic memory. When I sit alone in a hotel and picture my wife waving goodbye at the airport the day before, my experience is not at all in the business of denying my wife's existence. On the contrary, it casts my wife as real but not here, or as Sartre puts it, "as existing elsewhere." The reason I miss my wife even more when I picture her thus is precisely that the experience represents-as-absent something otherwise real.

If all this is right, then we can refine I2.1-I2.3 to target these three specific types of imagery. Thus:

(I2.1) Mnemonic experience $E$ represents-as-absent $O$.

(I2.2) Imaginative experience $E$ represents-as-non-existent $O$.

(I2.3) Phantasmagoric experience $E$ merely-represents $O$.

Since our concern in this paper is the relationship between perception and imagination, what matters for our purposes is the contrast between P2 and I2.2. The contrast is extremely straightforward on this Sartrean account: it is the contrast between representing-as-existent and 
representing-as-non-existent. What is not straightforward is the notion that these are two attitudinal features that mark a categorical difference between the phenomenology of perception and imagination. These attitudinal features are moreover constitutive of perception and imagination-they are what makes a given experience perceptual or imaginative:

These positional acts [captured in I2.1-I2.3] - this remark is of the first importance (est capitale) - are not superadded to the image once it is constituted: the positional act is constitutive of the image-awareness (conscience d'image).

(Sartre 1940, p. 24/2004, p. 13; my translation)

Thus the overall view is that there is not only a functional but also a phenomenal difference between perceiving and imagining. Far from being a difference in degree, this is a difference in kind, as each presents what it does in its own sui generis way. These "ways of presenting" are felt attitudinal features: just as conscious belief that $p$ involves feeling it true that $p$ whereas conscious desire involves feeling it good that $p$, so perceiving $O$ involves feeling $O$ to be real, whereas imagining $O$ involves feeling $O$ to be unreal.

Observe that this view, like the version of ND that Sartre failed to address (the aforementioned lacuna in his argument), appeals crucially to the difference between reality and unreality in distinguishing perception and imagination. However, while that version of ND builds the reality/unreality difference into the content of accompanying beliefs, the present view builds it into the attitude employed by perception and imagination themselves. This seems to me to have at least two major advantages. First, it vindicates the intuition that there is some difference between the experiences of perception and imagination themselves, regardless of accompaniments. Secondly, it makes room for a perception/imagination distinction even in creatures completely lacking in the capacity for propositional thought-something that the appeal to beliefs about reality and unreality appears to rule out.

Sartre's initial account, thus understood, has a clear answer to $Q 1{ }_{p}$ and $\mathrm{Q}_{\mathrm{p}}$. The phenomenal similarity between perceptual and imaginative experience is in content: what is represented in consciousness is the same. The phenomenal dissimilarity is in attitude: how it is represented is different. As we will see in the next section, however, Sartre's considered view is more complex than this.

I close this section with a historical note on the intellectual lineage of the attitudinal account from Brentano through Husserl to Sartre; readers uninterested in questions of historical development may skip directly to the next section.

Sartre heard of Husserl from his friend Raymond Aron, upon the latter's return from a year at the French Institute in Berlin. Sartre, 28 at the 
time, was immediately enthralled by the notion of "making philosophy out of real life" (that was the gist of Aron's presentation), and spent the following academic year (1933-34) at the Institute reading mostly Husserl, Scheler, Faulkner, and Kafka-and writing a brief note on intentionality as the fundamental notion in Husserl's philosophy (Sartre 1939; see Contat and Rybalka 1970, p. 71). Sartre credits Husserl with the attitudinal account of the perception/imagination distinction: the fourth and final chapter of The Imagination is titled simply "Husserl." And indeed, Husserl does develop such an account, though in his characteristically dense style (Husserl 1913, $\S \S 111-114)$. As noted above, however, the general approach of classifying mental states according to their attitudinal properties is central in Brentano's philosophy. Now, Husserl studied with Brentano in Vienna between 1884 and 1886, at the impressionable age of 25-27, and when Brentano's Psychology had already gained notoriety (indeed, had become a young orthodoxy in some quarters).${ }^{34}$ Furthermore, Brentano's attitudinal distinction between belief and desire, or more generally, his classification of mental states, is adopted virtually as-is by Husserl (1901, Investigation V, Chs. 4-5). ${ }^{35}$ This raises the question of whether Husserl might have been influenced by Brentano in developing his attitudinal account.

It is highly plausible that Husserl was strongly influenced by Brentano's general way of thinking in terms of attitudinal differences and similarities. But might he have been influenced specifically with respect to the perception/imagination distinction?

In the Psychology, Brentano mentions the imagination about a dozen times in all, always in passing. In fact, in the entire Brentano corpus there is only one sustained discussion of the imagination. This is in the context of his lecture notes for a course on "Selected Questions from Psychology and Aesthetics" (published posthumously in Brentano 1959). Much of this course was dedicated to the concept of imagination or fancy (Begriff der Phantasie)..$^{36}$ Brentano covers many issues related to this topic, and in a somewhat confusing way, but as Tănăsescu (2010) shows, "the fundamental idea of the [relevant] text is that perceptual representation and imaginative representation in the improper sense are different in their . . . modality of representation" (Tănăsescu 2010, p. 58).$^{37}$ In other words, the difference is in the attitudinal features exhibited.

Interestingly, the course was offered at the University of Vienna in the academic year 1885-1886, so just during the window of time Husserl was there. There is every reason to believe that Husserl sat in on that course. If so, what he heard there may well have had a direct impact on what he wrote much later in the Ideen (Husserl 1913). ${ }^{38}$ Now, there is no reason to suppose that Brentano's attitudinal distinction appeals to the presence or absence of representing-as-existent. Brentano speaks, somewhat opaquely, of perceptual representation being "intuitive" and imaginative representation being "conceptual with an intuitive core." ${ }^{99}$ But then again, the distinction in terms of representing-as-existent and contrasting attitudinal 
features is not all that transparent in Husserl either. In truth it becomes clearly articulated only with Sartre.

What Sartre seems unaware of, however, is the deep influence Brentano's thought exercised on Husserl's. In this, he is representative of French phenomenology at large. There is no more awareness of Husserl's debt to Brentano in Levinas, Merleau-Ponty, de Beauvoir, and Ricœur. In general, Brentano's work has seen much less uptake in French philosophy than its German, Polish, and Italian counterparts. ${ }^{40}$ The renowned medievalist Étienne Gilson discussed Brentano's interpretation of medieval philosophy in a 1939 piece (Gilson 1939), and his daughter Lucie Gilson offered the first systematic French-language exposition of Brentano only in the 1950s (Gilson 1955a, 1955b). Other than that, there is very little discussion of Brentano before the last quarter of the twentieth century. All the same, it is fair to say that Sartre's specific attitudinal account of the perception/imagination distinction is indirectly influenced by Brentano's attitudinal approach to mental classification and its public application to the perception/imagination distinction while Husserl studied with Brentano. $^{41}$

\section{A refined account?}

In the last 5-6 pages of The Imagination, Sartre argues that the attitudinal difference between perception and imagination, although central, cannot be the whole difference; there must be a difference in content as well (Sartre 1936, pp. 154-160/2012, pp. 137-142). My goal in this section is to argue that (i) Sartre's argument for this is uncompelling, but (ii) some plausible refinements of the last section's attitudinal account are nonetheless possible.

Sartre's argument is based on consideration of what happens, experientially and epistemologically, when we perform Husserl's "phenomenological reduction" on perception. In the phenomenological reduction, the subject "brackets" the reality of what she is aware of and considers only how it appears to her. Suppose I have a perceptual experience of my dog. To perform a phenomenological reduction on this experience is to bracket the reality of the dog and consider only how he appears to me in my experience: dog-shaped, mustard-colored, and so on. For Husserl, this means that the perceptual experience has undergone a "neutrality modification": the reality commitment built into its attitudinal character or mode of representing has been neutralized, canceled out. It is "a modification which, in a certain way, completely annuls, completely renders powerless every doxic modality to which it is related" (Husserl 1913, p. 257). Sartre observes that the possibility of neutrality modification of a perceptual experience raises a question: "how can one distinguish the centaur that I imagine from the blossoming tree that I perceive once the reduction is performed?" (Sartre 1936 , p. $154 / 2012$, p. 137). If the key difference between perception and 


\section{2}

Uriah Kriegel

imagination is the attitudinal feature of representing-as-existent involved in the former, then as soon as this representing-as-existent is neutralized through the reduction I should be unable to tell apart introspectively (thus bracketed) perception from imagination. Therefore:

the distinction between mental image and perception could not come from [modes or kinds of] intentionality alone. It is necessary but not sufficient that the [kinds of] intentions differ; it must also be that the matters are dissimilar.

(Sartre 1936, p. 159/2012, p. 141)

By "matters," Sartre clearly means something that contrasts with attitude or mode of representation-perhaps intentional content, but more likely what Husserl called the hyle: a proto-intentional aspect of experience that becomes intentional only by being "intentionally animated" (see Williford 2013 for recent clarification of this notion) ${ }^{42}$ Either way, the introspective discriminability of imagination and neutralized/reduced perception implies some non-attitudinal difference between them. ${ }^{43}$

We might reconstruct Sartre's argument as another epistemological argument by elimination. It starts from an epistemological "datum" regarding what we can know in a characteristically first-personal way: namely, whether we are having an imaginative or neutralized-perceptual experience. The best explanation is then claimed to appeal to first-person knowledge of some non-attitudinal difference between the two. More precisely: (1) imaginative experience and neutralized perceptual experience are introspectively discriminable; so, (2) there must be a phenomenal difference between them; but, (3) there is no attitudinal difference between them; therefore, (4) there must be some non-attitudinal difference between imaginative experience and neutralized perceptual experience. ${ }^{44}$

I am not going to challenge premise 1 , which seems to me antecedently plausible, nor the inference from 1 to 2 , which is required for all the epistemological arguments Sartre employs, including those endorsed above. But premise 3 is eminently objectionable. When a perceptual experience undergoes the neutrality modification, it may no longer have the attitudinal feature of representing-as-existent. Its commitment to the reality of the perceived object has been bracketed. But this does not mean that it has now acquired a new commitment, to the unreality of the object. On the contrary, it is genuinely neutral on the object's ontological status. Husserl himself notes that the neutrality modification is "a modification in a totally different sense than that of negation" (Husserl 1913, p. 257). ${ }^{45} \mathrm{In}$ contrast, the characteristic attitudinal feature of imaginative experiences is representing-as-non-existent, a kind of positive commitment to a specific ontological status of the object imagined. Thus there is still a clear attitudinal difference between imaginative experience and perceptual experience even after the neutrality modification. ${ }^{46}$ 
Sartre could overcome this specific objection by concentrating his argument on the contrast between neutralized perceptual experiences and neutralized phantasmagoric experiences. For, unlike imaginative experience, phantasmagoric experience does not involve representing-asnon-existent but only what we called above "attitudinally neutral" mererepresenting. Thus it might be suggested that neutralized perceptual and phantasmagoric experiences involve the same neutral(ized) attitude toward their represented object, and yet are introspectively discriminable. It would then be natural to suggest that their introspectively detectable difference must be non-attitudinal. ${ }^{47}$

The weak link in this revised argument is the notion that a neutralized representing-as-existent phenomenally feels the same as attitudinally neutral mere-representing. This conception of the phenomenological reduction casts it as genuinely altering one's commitments regarding reality and truth, if only for a moment. It is clear, however, that performing the phenomenological reduction involves no such thing. Instead, it involves an element of temporary pretense: one does not really change one's mind about how the world is, but assumes the position of someone who does. A phenomenologist standing on the train tracks and bracketing her perceptual experience of the coming train is fully alive to the approaching danger; she is thoroughly disposed to jump off the tracks in time to save her life. It is clear, then, that she continues to be attitudinally committed to the existence of the approaching train, even as she is engaged in her phenomenological exercises.

Compare: suppose $S$ believes that $p$, in fact has 97 per cent credence that $p$, and on this basis decides to $\varphi$; and suppose that someone asks $S$ whether $\varphi$-ing would still be appropriate if $S$ only had 50 per cent credence that $p$. In considering this, $S$ must perform a certain operation, but it is not part of the operation really to lower her credence by 47 per cent (even for a time); it involves something subtler, which we may describe as simulating having 50 per cent credence that $p{ }^{48}$ It would be most accurate to say that $S$ has a credence of 97 per cent and a pretend-credence of 50 per cent. Now, merely entertaining that $p$ is even more thoroughly neutral than having 50 per cent credence that $p$ : while the 50 per cent credence does not present $p$ as true, it does present $p$ as an object of truth evaluation; it "brings up" the issue of truth in a way mere entertaining does not. So, a more radical exercise $S$ might be asked to perform is to consider whether she would $\varphi$ if she had no credence whatsoever in $p$ but merely entertained that $p \cdot{ }^{49}$ Again, to consider the matter, $S$ would need to perform a certain operation, but it is not part of this operation to stop having any commitment on the likely truth of $p$; it only involves pretending or simulating having no such commitment.

The analogy to the perception/phantasm case is clear. Just as belief involves the attitudinal feature of representing-as-true whereas entertaining is attitudinally neutral, so perceptual experience involves the attitudinal feature of representing-as-existent whereas phantasmagoric experience is 


\section{Uriah Kriegel}

attitudinally neutral. A subject who performs the phenomenological reduction on a perceptual experience of a coming train does not eliminate her commitment to the existence of the train any more than $S$ stops being committed to the likely truth of $p$. It is a good question what does happen when one performs a phenomenological reduction on one's train perception..$^{50}$ But whatever it is, it cannot involve annihilation without trace of the original attitudinal features of the experience. So it is not true that there is no attitudinal difference between neutralized-perceptual and phantasmagoric experiences. The argument that there must also be a content difference therefore fails.

$$
\infty 2
$$

Nonetheless, Sartre's attitudinal account could bear refinement. Perhaps its most notable phenomenological incongruence concerns the contrast between perception and the imagery involved in episodic memory. It is true that perception presents its object as present, "in the flesh" (to use Husserl's expression), whereas in episodic memory we are aware of the object as in some sense absent. But surely the deeper phenomenal difference between the two pertains to time. When I reminisce about meeting my dog for the first time, so little and fearful with his penetrating eyes, I have a mnemonic experience whose content may well be identical to that of the perceptual experience I underwent that day. ${ }^{51}$ But the overall phenomenal character of the two experiences is certainly different, most perspicuously insofar as my current mnemonic experience presents the relevant scene as in the past, whereas my past perceptual experience presented the very same scene as in the present. ${ }^{52}$ This phenomenal difference is not captured by the distinction between representing-as-existent and representing-asabsent, at least not in any direct or obvious way.

To account for this central phenomenal difference, the Sartrean should take another leaf from Brentano and introduce a second set of attitudinal features, pertaining specifically to time. The relevant distinction Brentano posits is between modus praesens and modus passens, as two manners or ways of representing objects:

Above all we must designate temporal differences as modes of presentation. Anyone who considered past, present, and future as differences in objects would be just as mistaken as someone who looked upon existence and nonexistence as real attributes.

(Brentano 1911, p. 279; see also Brentano 1928 Ch.5, esp. § 12)

For Brentano, just as existence and non-existence are not really properties that some objects instantiate and others do not, so presentness and pastness (and futureness) are not really properties of objects. Rather, just 
as some objects are represented-as-existent and others are represented-asnon-existent by categorically different mental states, so some objects are represented-as-present and others represented-as-past by categorically different mental states. In the first case, the relevant states are perceptual and imaginative; in the second, perceptual and mnemonic. Thus the deep phenomenal difference between mnemonic and perceptual experiences is best captured not by $\mathrm{I} 2.1$ and $\mathrm{P} 2$ but by:

(I2.1*) Mnemonic experience $E$ represents-as-past $O$.

(P2*) Perceptual experience $E$ represents-as-present $O$.

As for imaginative and phantasmagoric experiences, there are several ways to construe their characteristic attitudinal temporal tag, but perhaps the most natural is to suppose it is "attitudinally neutral," that is, that they represent their objects without any temporal orientation. ${ }^{53}$ This would not rule out imagining or fantasizing something as in the past, in the present, or in the future; it would merely require building that temporal reference into the content of the relevant act. ${ }^{54}$

The key to this Brentanoian refinement of Sartre's attitudinal account is the notion that not all attitudinal phenomenal differences must be accounted for in terms of a single set of attitudinal features. In addition to attitudinal features pertaining to the ontological status of the represented objects, Brentano posits also attitudinal features pertaining to their temporal and modal status. ${ }^{55}$ (In the last case, Brentano's distinction is between apodictic and assertoric attitudes: the former represents-as-necessary $p$, the latter represents-as-contingent $p$-see Brentano 1889, p. 82 and Brentano 1933, p. 25.) For Brentano, the ultimate classification of mental states is determined by the various combinations of compossible attitudinal features exhibited by states. Thus perceptual experience not only represents-asexistent but also represents-as-present and represents-as-contingent. It contrasts with mnemonic experience insofar as the latter represents-as-past, but with imaginative experience insofar as the latter represents-as-non-existent (and perhaps with intuitional experiences insofar as those represent-asnecessary). ${ }^{56}$ Thus there need not be a single attitudinal dimension along which perception contrasts with all types of non-perceptual experience with potentially the same content as it.

It might be objected that there are no phenomenal differences between perception and imagery pertaining to time and modality, and any sense of such difference derives from accompanying beliefs: when I reminisce about meeting my dog for the first time, I believe that the scene I am aware of occurred in the past. ${ }^{57}$ The experiential awareness itself, however, is silent on the scene's time.

This alternative account parallels, of course, what we called ND. But there is no reason to suppose it more plausible. In particular, it will be 


\section{Uriah Kriegel}

hard-pressed to account for the first-person knowledge we have of whether we are perceiving or episodically remembering. Thus, patients suffering from source amnesia have episodic memories of past events without knowing when or where they acquired those memories, nor when or where the remembered events took place. Nevertheless, they still do seem to themselves to be remembering the relevant scenes. That is, they experience their episodic memories as memories, and can introspectively recognize them as such. They are not inclined to mistake them for perceptions or imaginations. What source amnesiacs appear to lack is the ability to generate certain beliefs about the events they seem to themselves to remember. Nonetheless, they experience a phenomenology of pastness they can introspectively detect. ${ }^{58}$

\section{Conclusion}

To summarize, contrary to a long Anglo-Saxon tradition, dating back at least to Hume, Sartre convincingly argues that there must be a categorical distinction between perception and imagination, a distinction in kind and not merely degree. This difference pertains to the manner in which the object perceived or imagined is represented in consciousness, that is, the kind of attitude consciousness bears to its content. The difference is that perception represents-as-existent its object, whereas imagination represents-as-non-existent its. Sartre also flirts with the notion of a content difference between the perception and imagination, but this may be just another infelicitous Sartrean flirtation.

As noted, this account provides us with answers the two questions we started with: $\left(\mathrm{Q}_{\mathrm{p}}\right)$ What is the phenomenal similarity between perceiving $O$ and imagining $O$ ? $\left(\mathrm{Q}_{\mathrm{p}}\right)$ What is the phenomenal dissimilarity between perceiving $O$ and imagining $O$ ? The answer to $\mathrm{Q} 1$ is straightforward: perception and imagination are phenomenally similar in having the same kind of content. The answer to $\mathrm{Q}_{\mathrm{p}}$ is also simple once we appreciate it: perception and imagination are phenomenally dissimilar in that they employ different kinds of attitude-the manner in which they represent what they do is categorically, qualitatively different. In a slogan: perception and imagination are similar in content, dissimilar in attitude.

This answer to our organizing question also sketches a phenomenological account of the nature of imagination-as well as of perception. It is perfectly possible that the deepest nature of imagination and perception is functional, that is, to be given by exhaustive specification their functional role within the cognitive architecture of the mind. But our concern here has been with the phenomenological approach to mental life. Phenomenologically, the nature of imagination is given by its distinctive attitude, its representing-as-non-existent character. More fully, we may propose the following phenomenological existence and identity conditions for imaginative experiences: 
For any imaginative experience $E, E$ is the imaginative experience it is (rather than another imaginative experience) because it bears the content it does (and not another), and $E$ is an imaginative experience at all (rather than a non-imaginative experience) because it employs the attitude it does (and not another).

For example, an imaginative experience as of a mustard-colored dog is the imaginative experience it is because it is as of a mustard-colored dog and is an imaginative experience at all because it represents-as-non-existent that mustard-colored dog. The first half of this provides the (phenomenological) identity conditions of imaginative experiences, the second their (phenomenological) existence conditions. I leave the formulation of the parallel phenomenological existence and identity conditions of perceptual, phantasmagoric, and mnemonic experiences as an exercise for the reader.

Remarkably, the assumptions needed to establish this kind of attitudinal approach to imaginative phenomenology are rather innocuous. One assumption is that imaginative and perceptual experiences can have the same content; not that they always or even typically do, but just that they can. ${ }^{59}$ The second assumption is that even when they do, the subject can have a distinctively first-personal knowledge of which state she is in; not infallible or even privileged or otherwise privileged knowledge, but just distinctive knowledge. If these two assumptions are granted, it is hard to see how to avoid the attitudinal account of imaginative phenomenology. According to it, there is a categorical difference between imaginative and perceptual phenomenology. ${ }^{60}$

\section{Notes}

1 In fact, there is not only a bewildering variety of imaginings, but also a considerable variety of axes along which they can be distinguished. Here I will distinguish them in terms of their intentional character, but there are other ways to distinguish very finely varieties of imagination (see, e.g., Stevenson 2003). Many have concluded that there is no hope of finding a commonality among all types of imagination (see Strawson 1970). A more sustained argument for the fundamental heterogeneity of imagination is provided by Kind (2013). This seems to me an overreaction, but I bracket the issue here.

2 When I imagine seeing a dog, there is a further distinction between imagining myself as part of the scene, with the imaginative state representing explicitly both the dog and me, and imagining the scene as seen from my viewpoint, construed as a sort of zero point of perceptual space.

3 It may turn out that this conceptual claim is too strong, and there are some conceptually possible propositional imaginings that involve no sensory imagery. Still, a softer claim in the same spirit (about typical or normal or paradigmatic instances, say) is surely right.

4 Byrne (2010) raises Q1 and Q2 (extended to cover episodic memory) as well, but cites functional (dis) similarities to answer them, which suggests that his concern is not with $\mathrm{Q} 1_{\mathrm{p}}$ and $\mathrm{Q} 2 \mathrm{p}$ but with their functional analogs. 


\section{Uriah Kriegel}

5 Thanks to Margherita Arcangeli for helping me see this.

6 On this view, what it is like to have a perceptual experience of a dog and an imaginative experience of a dog (at the same distance, of the same shape and color, etc.) is strictly the same. The difference between them is entirely nonphenomenal: the former is, whereas the latter is not, accompanied by the belief that there really is such a dog before one. The view is discussed somewhat sympathetically by Russell (1921, Ch. 8), who nonetheless does not end up endorsing it, despite adopting an analogous view regarding the difference between perception and episodic memory (1921, Ch. 9).

7 Hume writes: "An idea assented to FEELS different from a fictitious idea, that the fancy alone presents to us: And this different feeling I endeavour to explain by calling it a superior force, or vivacity, or solidity, or FIRMNESS, or steadiness" (Treatise, I.iii.vii; emphasis original).

$8 \mathrm{DD}$ is intended to exclude $\mathrm{KD}$, something that the present formulations leave to implicature. We can fix this by adding "mere" to DD, or else defining the second account of the relationship between perceptual and imaginative phenomenology in terms of DD\& KD. In all three theses, we probably have to add a qualifier such as "topically."

9 The notion of episodic memory comes from Tulving (1972), who contrasted it with "semantic memory," which concerns remembering certain impersonal facts (as when I remember that Pope Benedict IX was 11 years old when he was elected to the papacy). Tulving himself characterized episodic memory as concerned exclusively with "personally experienced events" (Tulving 2001: 1506), but, as Byrne (2010) shows, this is unduly restrictive. The distinguishing characteristic of episodic memory is that it is imagistic or sensory.

10 We may consider (non-lucid) dreams prolonged phantasma, given their production by subpersonal processes consciously uncontrollable by the person.

11 Throughout both books and without argument, Sartre assumes that for his purposes what I have called imaginative and phantasmagoric phenomena "belong together"; his stance toward episodic memory is a bit ambiguous. But the three appear on their face to share something rather essential. From the perspective of $\mathrm{KD}$, ultimately one might say that there is a phenomenal determinable $\mathrm{D}$ that all three instantiate but perceptual experience (for example) does not, or more minimally that there is another phenomenal determinable $\mathrm{D}^{*}$ that perceptual experience instantiates but none of these three does. (As I understand him, Sartre assumes the first, stronger claim. We will have occasion to revisit this assumption later on.) It is an open question, in any case, whether the distinctions drawn above with respect to imagination (propositional vs objectual imagining, etc.) apply to phantasm and episodic-memory imagery. It is highly plausible that they do, but I will not assume as much here.

12 The relationship between the two is not altogether clear in the text. In The Imagination (Sartre 1936), the fact that there are two prima facie independent (though clearly related) tenets is not transparent in the text. Only in The Imaginary (Sartre 1940) does it become explicit, and the classical conception is accused of a "double error" (1940, p. 14/2004, p. 5). This duality is entirely missed by Merleau-Ponty in his review of The Imagination (Merleau-Ponty 1936), which focuses entirely on the first tenet (admittedly more pronounced in the first three chapters of The Imagination).

13 I will often stick to the excellent English translations now available of Sartre's two books. Occasionally, however, I will offer my own translation, rarely very 
different from the published ones. (There is only one significant translator's decision I have made-see note 24). I will always indicate when I do. In any case, with quotes from Sartre I will always cite both the French original and the English edition; for quotes from other sources I will only cite the English edition. Quotes from the French original of Sartre (1936) will refer to the 1983 reprint by Presses Universitaires de France; those of Sartre (1940) refer to the first edition.

14 This is to be contrasted with any intrinsic features of the experiences considered in isolation; hence Sartre's emphasis in the quoted text.

15 If we wanted to formulate the argument with greater precision, we might offer: for some subject $S$ and any experience $E$, such that $S$ is a healthy human adult in normal circumstances and $E$ is either a perceptual experience or an imaginative experience, 1) $S$ knows whether $E$ is perceptual or imaginative immediately; 2) if ND, then $S$ would not know whether $E$ is perceptual or imaginative immediately; therefore, 3) ND.

16 To that extent, the claim is not undermined by the Perky experiment, where subjects asked to imagine bananas while staring at blank screen were shown (unbeknownst to them) increasingly clearer banana images on the screen but failed to realize they were now perceiving rather than (merely) imagining bananas (Perky 1910). As an alleged demonstration that we are unable introspectively to tell apart perception from imagination, the experiment suffers from a variety of difficulties (see Casey 2000, 149 for a notable one). But in any case, since the circumstances of the experiment are atypical and far from ordinary, they do nothing to undermine the claim Sartre needs for his argument.

17 For my part, I have argued for a relevant similar epistemology of first-person knowledge in Kriegel (2011, Ch. 1, 2013). In the latter, I present and defend a model of first-person knowledge as based on simple endorsement of introspective appearances: one knows that one is having perceptual experience $E$ by having an introspective appearance as of having $E$ and endorsing that appearance. If either introspection or endorsement malfunctions, one is liable to end up with a false first-person belief, or fail to form a true first-person belief. Thus neither infallibility nor self-intimation holds.

18 We may represent it as follows: 1) if ND were true, acquiring knowledge of whether one is perceiving or imagining would be considerably more effortful than it in fact is; therefore, 2) ND is false.

19 In sufficiently bizarre settings, I might be unsure whether I am perceiving Pierre or hallucinating him. But both perception and hallucination are perceptual experiences. Imaginative experiences are another thing still. In standard cases where I am unsure whether I am perceiving or hallucinating $O$, I am still certain that I am not imagining $O$.

20 Sartre appears to adduce two further arguments, but they are uncompelling.

21 Moreover, when we consider the lowest resolution a perceptual experience can have consistently with the laws of nature, it is hard to believe that no imaginative experience can match that level of accuracy.

22 Note: this argument does not require the claim that every perception of an opaque three-dimensional object involves imagining its invisible parts, the parts other than the directly visible surface (Nanay 2010). It only requires the claim that it is nomologically possible for us to perceive one part of such an object and imagine another simultaneously, and in such a way that the characteristics attributed to each part differ. 
23 Thanks to Matthew Eshleman for helping me see more clearly the dialectical circumstance here.

24 In this passage (and others), I have translated "conscience" as awareness rather than consciousness. In French, the word "conscience" is much more elastic than in English. For example, it covers also conscience (e.g., political or moral). As part of this, it is noteworthy that there is no distinct word for awareness in French. When "conscience" occurs in a noun, or its cognate as an intransitive verb, it is natural to translate it as "consciousness"; but when it occurs as a transitive verb, it seems to me much more natural to translate it as "awareness." Although this is not a common practice in translation of French phenomenological text, in my opinion it should be.

25 Whether in doing so Sartre anticipates also "the transparency of experience" (Harman 1990), "representationalism" (Dretske 1995), or "intentionalism" (Byrne 2001) is a more delicate question. Sartre clear thinks that all introspectively accessible aspects of experience are intentional. However, as we will see in the section on Sartre's attitudinal account, he does not think that all introspectible aspects of an experience pertain to what is presented by the experience; some pertain to the presenting of whatever is presented. This would not qualify as transparency or representationalism/intentionalism by most contemporary standards. For a recent argument that Sartre is an early intentionalist, see Rowlands (2013).

26 Similar remarks are made in The Imaginary: "whether I perceive or imagine this chair, the object of my perception and that of my image are identical: it's this straw chair on which I sit. It is simply that consciousness relates to this same chair in two different ways. In both cases, I target the chair in its concrete individuality, in its corporeality. Only in one case, the chair is 'encountered' by consciousness: in the other, it is not" (1940, p. 7; my translation, italics original). The passage from The Imagination quoted in the main text is still the clearest and most explicit.

27 This is not Sartre's terminology—in fact, Sartre is quite hostile to describing conscious episodes as mental states. Here and in the remainder of the paper, I use the expression as it is standardly used in contemporary analytic philosophy of mind-to denote more or less what Descartes called "thoughts."

28 Indeed, $S$ s belief that $p$ and desire that $p$ may be components of a single state, say her being glad that $p$. One might argue that in such a case the intensity of her belief and desire states is just the intensity of her gladness state, and therefore the same. (The assumption would be that a state such as gladness cannot vary in intensity across its different "components.")

29 The full sentence ending this passage is "It would be better to say "consciousness of Pierre-as-imaged' or 'imaging consciousness of Pierre'." I excised the expression "consciousness of Pierre-as-imaged" because it seems to me to suggest, misleadingly, a content property of the relevant consciousness (or awareness). It might be claimed that it undermines my attitudinal interpretation of Sartre's account, but given the rest of the text, it rather seems like an instance of carelessness on Sartre's part. Or, perhaps more charitably: Sartre may have in mind here that imaged-Pierre is a sort of "formal object" of the image that must be distinguished from its intentional object. Consider being afraid of a dog. It is commonly claimed, and quite plausibly, that the formal object of fear is danger. But this is not to be understood as part of the intentional object/content of fear: 
what one is afraid of, after all, is just the dog-not the dog's dangerousness. Talk of formal objects seems to be elliptical for something more fundamental. Arguably, this "something" is an attitudinal feature of mental states. Thus, it is an attitudinal feature of fear that it represents-as-dangerous what it does.

30 The notion that belief and desire have characteristic or proprietary phenomenal properties is often referred to as cognitive phenomenology-see Bayne and Montague (2011) for a recent collection pertaining to it.

31 In some places, Sartre takes the last two to be different, thus suggesting that there are in fact four types of image: "the imaginary object can be posited as nonexistent, or as absent, or as existing elsewhere, or not be posited as existent" (Sartre 1940, p. 232/2004, p. 183). I am going to ignore this wrinkle, nowhere motivated by Sartre, in my present discussion.

32 Interestingly, the existence of such attitudinally neutral mental states is recognized by Brentano, where they are claimed to constitute the third fundamental category of mental states, in addition to cognitive and conative attitudes. For Brentano, there are the categories of judgment and interest, but even more basic is the category of presentation (Vorstellung): while the latter is a component of all other attitudes, they are not components of it (see Brentano 1874, Book II, Chs 6-7).

33 Some might also hold that we cannot imagine Obama himself, as opposed to just an Obama-like object. Imaginative reference might be claimed to be "descriptive" rather than singular, putting together a number of feature representations but lacking any tracking relation in virtue of which to represent particulars. If so, the imaginative experience proper represents-as-non-existent an Obama-like object. This response to the objection strikes me as wrongheaded in a number of ways, but perhaps some readers would find it credible.

34 This was so especially in Vienna and Prague, then intellectual centers of the Austro-Hungarian Empire. In Vienna, Brentano himself wielded this influence, which extended beyond philosophy (for his place in the general cultural context, see Johnston (1972), esp. Ch. 20; for a fascinating analysis of his direct influence on Kafka, see Smith 1981). In Prague, it was Anton Marty, Brentano's student in Würzburg in 1868-1869, who presided over a philosophical scene centered on Brentanian philosophy (a scene which included the two chief organizers and propagators of the material from Brentano's literary estate, Alfred Kastil and Oskar Kraus). In those years, every Thursday a group of philosophers met at the Louvre café to debate the finest details of Brentano's thought.

35 As it was by many of Brentano's students, notably Marty (1908, Ch. 6). Interestingly, even Brentano's students who developed their own classifications of mental states did so by offering revisions to Brentano's classification, and while maintaining the attitudinal framework (see Meinong 1902, Ch. 1).

36 Under this heading Brentano enumerates a great variety of phenomena, including mere representations, feverish hallucinations, short-term episodic memories, dream representations, and more (see Brentano 1959, pp. 43-44, and for a systematic discussion, Tănăsescu 2010).

37 Part of what is confusing in Brentano's presentation is his distinction between representation in the proper and improper senses, which appears to do with this: in the improper sense representation is understood in terms of its object, what it represents; in the proper sense, it is understood in terms of that plus the mode or modality of representation, how it represents what it represents. In the 


\section{Uriah Kriegel}

proper sense, suggests Brentano, there is no difference between perception and imagination/fancy—but in the proper sense there is (see Brentano 1959, p. 83). As Tănăsescu shows, the notion of content is used by Brentano for the wider (finer-grained) proper conception of representation. Not fully appreciating this distinction, the editor of these lecture notes, Franziska Mayer-Hillerbrand, casually replaces mentions of "content" (Inhalt) with "object" (Gegenstand) in key passages; but the original manuscripts in Prague show that Brentano's own talk here is of content (Tănăsescu 2010, fn 31).

38 This is certainly Tănăsescu's view—see the last four pages of Tănăsescu (2010).

39 This is stated explicitly in manuscript Ps 78/2c, B 19759, discussed in Tănăsescu (2010). According to Tănăsescu, this difference amounts to the difference between sensory and non-conceptual representation in the perceptual case and more abstract and conceptual representation, but with the undefined "intuitive core" in the imagination case.

40 This is so even as many French phenomenologists were cool to Husserl's "transcendental turn" and sought a much more realist phenomenology, of the sort arguably already developed by Brentano.

41 As we will see toward the end of the section, A refined account?, Brentano's attitudinal framework is more flexible and at the same time more systematic than Sartre's, positing at least three dimensions along which mental states can differ in their attitudinal features. At the same time, it is only in Sartre's work that this framework reaches its most plausible development with respect to the specific question of the perception/imagination distinction.

42 The disadvantage in postulating a hyletic difference between perception and imagination, as opposed to a content difference, is in the mysterious air surrounding the notion of hyle. The advantage is that it does not seem immediately implausible the way a content difference does. Yesterday I saw a plane flying above my house. It is exceedingly plausible that today I can in principle imagine exactly what I saw yesterday-not something very similar to what I saw, but exactly what I saw. This means that I can have an imaginative experience with the exact same content as yesterday's perceptual experience, not just a content very similar to it but differing in some details. Likewise, I can episodically remember or fantasize (in the technical sense of having a phantasmagoric experience) exactly what I perceived-just as I can entertain or believe exactly the same thing, not just very similar things.

43 Sartre is unclear on what that non-attitudinal (hyletic or content-related) difference might be. In one place, he tentatively floats the possibility that "spontaneity" might be involved (Sartre 1936, p. 159/2012, p. 141). But later Sartre tells us that its spontaneity is a matter of imagination taking a non-thetic position toward itself (Sartre 1940, p. 26/2004, p. 14); this makes it sound like an attitudinal feature after all. Another suggestion might flow from Sartre's claim that the imagined object is always exhausted by what the imagining subject knows about it, whereas the perceived object overflows what the perceiving subject knows (Sartre 1940, pp. 20-21/2004, pp. 10-11); this is what Sartre calls the "quasi-observational" character of images. It might be claimed this means that perception and imagination differ in terms of their contents' openness to interpretation: one can perceive a duck-rabbit figure without the perception settling which one it is, but if one imagines a duck-rabbit figure, it must be qua duck or qua rabbit (see, e.g., Pylyshyn 2003). However, this account cannot 
explain ability to tell apart introspectively perception and imagination in cases not involving ambiguous figures.

44 Throughout this presentation of the argument, a perceptual experience that has undergone Husserl's neutrality modification is called a "neutralized perceptual experience."

45 Indeed, negation itself can undergo a neutrality modification, whereby "negating is no longer serious negating" (Husserl 1913, p. 258).

46 Furthermore, it is unclear what the argument's conclusion precisely shows. For there may be a non-attitudinal difference between imaginative experience and neutralized perceptual experience that does not pertain to their own phenomenal characters but to the processes leading up to them. Clearly, the process of performing a phenomenological reduction is a conscious, personal-level process. It is something that I do, not something that happens to me: a conscious, introspectively accessible process. The neutrality modification does not descend on my perceptual experience in the dark, without my awareness; it is the result of an operation that I myself consciously perform. Therefore, I should be able to tell by introspection not only that my neutralized perceptual experience has this content and that attitude, but also that it was formed by that particular conscious process which is the phenomenological reduction. Crucially, that process is absent in the formation of imaginative, phantasmagoric, and mnemonic experiences alike (and other introspectible processes are present at least in some of these). This could account for my first-person knowledge of which experience I am having.

47 The revamped argument would look like this: (1) neutralized phantasmagoric experience and neutralized perceptual experience are introspectively discriminable; so (2) there must be a phenomenal difference between neutralized phantasmagoric experience and neutralized perceptual experience; but (3) there is no attitudinal difference between neutralized phantasmagoric experience and neutralized perceptual experience; therefore (4) there must be some non-attitudinal difference between neutralized phantasmagoric experience and neutralized perceptual experience.

48 Presumably, the purpose of this is to consider what actions the latter recommends. In this respect, the operation is akin to supposing or hypothesizing that $p$ in the context of seeing what might follow from it. By the same token, the purpose of performing the phenomenological reduction is presumably to facilitate appreciation of the different appearances subtended by the object, in accordance with Husserl's method for phenomenological inquiry.

49 By "no credence whatsoever" I do not mean a credence of $0 \%$, but rather lack of any assignment of credence.

50 One model might be that one simply adds a new experience to one's train perception, namely, a "pretend phantasm" of a train. Here there is not so much a neutrality modification as a neutrality addition. Another model is that one's perceptual experience is modified in such a way that it no longer exhibits representing-as-existent, but a subtler attitudinal feature we may call bracketedrepresenting-as-existent. Here there is a neutrality modification, but its result is not simple mere-representing that lacks any traces of the original, neutralized experience; on the contrary, every neutralized state exhibits its own special attitudinalfeature (bracketed-representing-as-trueforbelief, bracketed-representingas-good for desire, and so on). 


\section{Uriah Kriegel}

51 It is of course possible that I am misremembering certain details of that encounter, or have an indeterminate mnemonic representation of a scene whose perceptual representation was fully determinate. But we can readily conceive of a pair of experiences, one perceptual and one mnemonic, for which the content really is identical.

52 This phenomenological claim, like any other, may be reasonably denied. I will consider the main objection to it at the end of this section. But a more minor objection can be addressed now: that unrecognized episodic memories and cases in which one is unsure whether one is remembering or imagining show that a feeling of pastness cannot be part of the very phenomenology of memory. Somewhat paradoxically, such objections falter on the assumption that phenomenology must always be self-intimating and introspection always infallible. Otherwise, we can suppose that unrecognized memories, and memories undistinguished from imaginations, have a phenomenology of pastness that introspection, being less than omnipotent, simply misses out on.

53 With this Brentano may disagree, however. He writes that "no presentation could fail to have a temporal mode" and "it is impossible to have a presentation of something with a general temporal mode, as though a thing might appear indeterminately as past, future [etc.]" (Brentano 1911, p. 280). However, I am unaware of any argument for this provided by Brentano.

54 Compare: desiring ice cream represents-as-good ice cream; believing that ice cream is good also represents ice cream as good, but it does so as part of the content believed, not as part of the mode of representing (that is, it representsas-true that ice cream is good, which is structurally very different from representing-as-good ice cream).

55 A vague sense of plausibility attaches to this extension when we consider that existence, time, and modality have presented distinctive but often parallel challenges in metaphysics.

56 For example, when the occurrent intuition that identity is transitive dawns on one, it represents-as-necessary the transitivity of identity. It may also be held that, unlike perceptual experience, imaginative experience represents-as-possible. It is often thought that imagination represents possibilia (we cannot imagine a square circle, for example). If one held that it represents them as possibilia, one could also maintain that it is characteristic of imaginative experience of $O$ that it represents-as-possible $O$; this would be a modal-attitudinal feature of imagination.

57 This is clearly Russell's view of memory: "Memory demands (a) an image, (b) a belief in past existence. The belief may be expressed in the words "this existed"" (Russell 1921, p. 155).

58 Source amnesia has been known since the later 1950s (see Evans and Thorne 1966), and has been rigorously studied in experimental settings at least since the mid-1980s (see Schacter et al. 1984).

59 Thus we may concede that typically the content of perception presents a higherresolution scene than that of imagination-as long as sometimes the resolution can be the same. Likewise, we may note that perceptual experience always presents its object as spatially located relative to the subject, whereas it is possible to imagine the same object in an entirely aspatial manner-as long as it is also possible to imagine the object as spatially located just the way a perceived object is spatially located. 
60 This work was supported by the French National Research Agency grants ANR11-0001-02 PSL* and ANR-10-LABX-0087. For comments on a previous draft, I am grateful to Margherita Arcangeli, David Chalmers, Matthew Eshleman, Jonathan Webber, and Kenneth Williford. For useful conversations, I would like to thank Margherita Arcangeli, Joëlle Proust, and Kenneth Williford.

\section{References}

Bayne, T. and M. Montague 2011. Cognitive Phenomenology. Oxford: Oxford University Press.

De Beauvoir, S. 1960. The Prime of Life. Trans. P. Green. New York: Paragon, 1992.

Brentano, F.C. 1874. Psychology from an Empirical Standpoint. Trans. A.C. Rancurello, D.B. Terrell, and L.L. McAlister. London: Routledge and Kegan Paul, 1973.

Brentano, F.C. 1889. The Origin of Our Knowledge of Right and Wrong. Trans. R. Chisholm and E.H. Schneewind. London: Routledge and Kegan Paul, 1969.

Brentano, F.C. 1911. Appendix to the Classification of Mental Phenomena. In Brentano 1874.

Brentano, F.C. 1928. Sensory and Noetic Consciousness. Ed. O. Kraus, Trans. M. Schättle and L.L. McAlister. London: Routledge and Kegan Paul.

Brentano, F.C. 1933. The Theory of Categories. Ed. A. Kastil. Trans. R.M. Chisholm and N. Guterman. The Hague: Martinus Nijhoff, 1981.

Brentano, F.C. 1959. Grundzuge der Ästhetik. Ed. F. Mayer-Hillerbrand. Bern: Francke Verlag.

Byrne, A. 2001. Intentionalism Defended. Philosophical Review 110: 199-240.

Byrne, A. 2010. Recollection, Perception, Imagination. Philosophical Studies 148: 15-26.

Casey, E. 2000. Imagining: A Phenomenological Study, 2nd ed. Bloomington: Indiana University Press.

Cohen, L.J. 1992. An Essay on Belief and Acceptance. Oxford: Clarendon.

Contat, M. and M. Rybalka 1970. Les Écrits de Sartre. Paris: Gallimard.

Currie, G. and I. Ravenscroft 2002. Recreative Minds: Imagination in Philosophy and Psychology. Oxford: Oxford University Press.

De Beauvoir, S. 1960. The Prime of Life. Trans. P. Green. New York: Paragon, 1992.

Dretske, F.I. 1995. Naturalizing the Mind. Cambridge, MA: MIT Press.

Evans, F.J. and W.A. Thorn 1966. Two Types of Posthypnotic Amnesia: Recall Amnesia and Source Amnesia. International Journal of Clinical and Experimental Hypnosis 14: 162-179.

Gilson, E. 1939. Franz Brentano's Interpretation of Mediaeval Philosophy. Mediaeval Studies 1: 1-10.

Gilson, L. 1955a. La psychologies descriptive selon Franz Brentano. Paris: Vrin.

Gilson, L. 1955b. Méthode et métaphysique selon Franz Brentano. Paris: Vrin.

Harman, G. 1990. The Intrinsic Quality of Experience. Philosophical Perspectives 4: $31-52$.

Hume, D. 1739. A Treatise of Human Nature. http://ebooks.adelaide.edu.au/h/ hume/david/h92t/index.html

Husserl, E. 1901. Logical Investigations, Vol. II, trans. D. Moran. London: Routledge, 1970.

Husserl, E. 1913. Ideas Pertaining to a Pure Phenomenology and a Phenomenological Philosophy (Vol. 1). Trans. F. Kersten. Dordrecht: Kluwer, 1982.

Johnston, W.M. 1972. The Austrian Mind. Berkeley, CA: California University Press. 


\section{Uriah Kriegel}

Kind, A. 2001. Putting the Image Back in Imagination. Philosophy and Phenomenological Research 62: 85-109.

Kind, A. 2013. The Heterogeneity of the Imagination. Erkenntnis 78: 141-159.

Kriegel, U. 2011. The Sources of Intentionality. Oxford and New York: Oxford University Press.

Kriegel, U. 2013. A Hesitant Defense of Introspection. Philosophical Studies 165: $1165-1176$.

McGinn, C. 2004. Mindsight: Image, Dream, Meaning. Cambridge, MA: Harvard University Press.

Marty, A. 1908. Untersuchungen zur Grundlegung der allgemeinen Grammatik und Sprachphilosophie. Halle: Max Niemeyer.

Meinong, A. 1902. On Assumptions. Trans. J. Heanue. Berkeley, CA: University of California Press, 1983.

Merleau-Ponty, M. 1936. L'imagination. Journal de Psychologie Normale et Pathologique 33: 756-761.

Nanay, B. 2010. Perception and Imagination: Amodal Perception as Mental Imagery. Philosophical Studies 150: 239-254.

Perky, C.W. An Experimental Study of Imagination. American Journal of Psychology 21: 422-452.

Pylyshyn, Z.W. 2003. Seeing and Visualizing. Cambridge, MA: MIT Press.

Rowlands, M. 2013. Sartre, Consciousness, and Intentionality. Phenomenology and the Cognitive Sciences 12: 521-536.

Russell, B. 1921. The Analysis of Mind. London: Routledge, 1995.

Sartre, J.-P. 1936. L'imagination. Paris: F. Alcan. Reprinted by PUF, 1983.

Sartre, J.-P. 1938. Structure intentionelle de l'image. Revue de métaphysique et de morale 45: 543-609.

Sartre, J.-P. 1939. Une idée fondamentale de la phénoménologie de Husserl: l'intentionalité. Nouvelle Revue Française 304: 129-131.

Sartre, J.-P. 1940. Limaginaire. Paris: Gallimard.

Sartre, J.-P. 2004. The Imaginary. Trans. J.M. Webber. London: Routledge.

Sartre, J.-P. 2012. The Imagination. Trans. K.W. Williford and D. Rudrauf. London and New York: Routledge.

Schacter, D.L., J.L. Harbluk, and D.R. McLachlan 1984. Retrieval without Recollection: An Experimental Analysis of Source Amnesia. Journal of Verbal Learning and Verbal Behavior 23: 593-611.

Smith, B. 1981. Kafka and Brentano: A Study in Descriptive Psychology. In B. Smith (ed.), Structure and Gestalt: Philosophy and Literature in Austria-Hungary and Her Successor States. Amsterdam: John Benjamins.

Stevenson, L.F. 2003. Twelve Conceptions of Imagination. British Journal of Aesthetics 43: 238-259.

Strawson, P.F. 1970. Imagination and Perception. In L. Foster and J.W. Swanson (eds.), Experience and Theory. Amherst, MA: University of Massachusetts Press.

Tănăsescu, I. 2010. Le concept psychologique de la représentation de la fantaisie et sa réception chez Husserl. Studia Phœnomenologica 10: 45-75.

Tulving, E. 1972. Episodic and Semantic Memory. In E. Tulving and W. Donaldson (eds.), Organization of Memory. New York: Academic Press.

Tulving, E. 2001. Episodic memory and common sense: How far apart? Philosophical Transactions: Biological Sciences 356: 1505-1515.

Williford, K.W. 2013. Husserl's Hyletic Data and Phenomenal Consciousness. Phenomenology and the Cognitive Sciences 12: 501-520. 